\title{
Attitudes towards catch-and-release recreational angling, angling practices and perceptions of pain and welfare in fish in New Zealand
}

\author{
R Muir ${ }^{\dagger}$, AJ Keown ${ }^{\ddagger}$ NJ Adams ${ }^{\dagger}$ and MJ Farnworth* ${ }^{* \dagger}$
}

\author{
+ Animal Welfare and Biodiversity Research Group, Department of Natural Sciences, Unitec Institute of Technology, Private Bag \\ 92025, Auckland, New Zealand \\ ${ }^{\ddagger}$ Institute of Veterinary, Animal and Biomedical Sciences, Massey University, Private Bag 1 1 222, Palmerston North 4442, New Zealand \\ * Contact for correspondence and requests for reprints: mfarnworth@unitec.ac.nz
}

\begin{abstract}
Although there is still some debate regarding whether fish have the capacity to feel pain, recent scientific research seems to support the notion that fish can indeed suffer. However, the continued scientific discourse has led to questions regarding how members of the public perceive issues of pain and welfare in fish. A questionnaire was developed and randomly distributed to 700 members of the general public in New Zealand. Questionnaires gathered basic demographic information, information regarding respondents' participation in and opinions on angling practice, and opinions about fish welfare and pain. The response rate was 62.4\% (437/700). The primary aim of the study was to assess public concerns for the impact of catch-and-release angling (CRA) on the welfare of fish. Most respondents indicated a belief that fish are capable of feeling some pain although older respondents scored the capacity of fish to feel pain lower than younger respondents. Likewise, most respondents believed that CRA causes pain and compromises survival in fish. Principle Component Analysis identified two major components within responses. These were: i) importance placed on good fishing techniques; and ii) concern for pain and survival of fish. Female respondents showed more concern about angling practices and their impact on pain and survival of fish than male respondents. Respondents who participate in CRA and considered it acceptable showed less concern for pain and survival in fish than both respondents who do not participate and those who considered CRA unacceptable. The majority of respondents considered angling an acceptable pastime (65\%; 284/435) but also indicated support for the introduction of guidelines and regulations to improve fish welfare in the future (76.4\%; 334/434). Those respondents that did not believe regulations were necessary provided statistically lower importance scores for both pain and survival in fish and good angling practices than respondents that did. Education about good angling practices may provide the best route by which fish welfare can be improved.
\end{abstract}

Keywords: angling, animal welfare, fish, pain, public attitudes, regulations

\section{Introduction}

Recreational angling is a long-established pastime practiced by many cultures around the globe (Davie \& Kopf 2006). Catch-and-release angling (CRA) is a branch of recreational angling in which caught fish are released either voluntarily or due to constraints imposed by harvest regulations (Cooke $\&$ Sneddon 2007). With the assumption that most of the released fish will survive, CRA is thought to be non-detrimental to fish stocks, and represents a sustainable method by which recreational fishing can continue to be enjoyed by many (Cooke \& Sneddon 2007; Rose 2007; Arlinghaus et al 2012). However, as discussions of fish welfare issues have arisen in both social and political arenas, concern over the ethicality of CRA has also grown, and the place of CRA in the future of recreational fishing is being called into question (Arlinghaus et al 2007, 2012).

The central question in the debate of whether CRA is ethical would have to be 'can fish feel pain?' If fish cannot feel pain it could be argued there is no welfare compromise for fish caught by angling, and therefore no further need for consideration to be given to angling practices. However, if fish do perceive pain and can suffer, the impact of capture on fish welfare could be significant. Furthermore, if angling does indeed constitute a welfare compromise for caught fish, CRA for the purposes of entertainment, becomes ethically questionable.

Currently, the dominant viewpoint among the scientific community is supportive of the notion that fish are capable of experiencing pain (Arlinghaus et al 2012), and several recent studies support this (Sneddon et al 2003; Dunlop et al 2006; Braithwaite \& Boulcott 2007). However, there continues to be some debate within the literature on the topic (Chandroo et al 2004; Arlinghaus et al 2009b, 2012) as neurological research on the capability of fish to experience pain remains limited (Davie \& Kopf 2006), and structures required for conscious perception (commonly accepted as being required for the experience of pain) 
remain unidentified in fish (Rose 2002, 2007). Furthermore, there is such great variety in both anatomy and physiology of fish species (Chandroo et al 2004; Rose 2007) it may, therefore, be inappropriate to extrapolate evidence amongst fish species (Cooke \& Suski 2005). Further research is required before we can speak confidently about the experience of pain for fish species.

The next question we should consider asking is 'how important is fish welfare?' Perhaps the most elegant way to approach the question is via quantitative means. As yet, there is no comprehensive publication quantifying the catch obtained by recreational fishing. However, Cooke and Cowx (2004) put forward a 'best guess' estimate of 47 billion fish per year landed by recreational anglers. The Food and Agriculture Organization of the United Nations (FAO) estimated the 2012 commercial fisheries catch at 90 million tonnes (FAO 2012). Using the assumed $0.635 \mathrm{~kg}$ per fish (as used by Cooke and Cowx 2004), this gives an estimate of over 141 billion fish per year landed by commercial anglers. While these figures are very rough approximations, it can be argued that when considered on a global scale, fishing most certainly affects enough individual fish for their welfare to warrant consideration.

There are contrasting opinions regarding the welfare issues raised by recreational angling (Arlinghaus et al $2009 \mathrm{~b}$ ) and much of the previous literature has focused on 'hooking mortality' (Bartholomew \& Bohnsack 2005; Cooke \& Suski 2005; Arlinghaus et al 2007). There has, however, been increased research into 'sub-lethal' effects in more recent studies. Physical trauma, physiological stress, and exhaustion resulting from the capture processes are arguably now the primary welfare concerns in recreational angling (Cooke \& Suski 2005; Arlinghaus et al 2007; Cooke \& Sneddon 2007). The effects of hook location, tackles/baits used, air exposure and handling time, duration of angling event, and angling during key life stages have been identified as factors impacting upon fish welfare during angling. All of which can be mitigated, to some extent, by anglers' attitudes and behaviour (Bartholomew \& Bohnsack 2005; Cooke \& Suski 2005; Davie \& Kopf 2006; Huntingford et al 2006; Cooke \& Sneddon 2007; Arlinghaus et al 2007; Arlinghaus et al 2009a; Cooke et al 2013). Because anglers' practices can have an effect on fish welfare during CRA, it may be advisable to implement educational material for recreational anglers which could potentially reduce the harm to caught fish.

General attitudes towards animal welfare have been explored extensively in the literature and there is an increasing body of knowledge addressing attitudes and behaviours of the general public and anglers in relation to angling practices, including CRA (Aas et al 2002; Environment Agency 2010; Hasler et al 2011; Wallmo \& Gentner 2011; Arlinghaus et al 2012; Dorow \& Arlinghaus 2012). However, this body of knowledge almost exclusively centres around the attitudes of people in the northern hemisphere (namely North America, the United Kingdom and
Europe), with some information to be found regarding attitudes in Australasia, and (as yet) no literature specifically addressing the attitudes of the New Zealand public. It is of particular interest to investigate the attitudes of New Zealanders, as recreational fishing is a well-established pastime for many, with $20 \%$ of the population estimated to engage in recreational angling (Ministry of Fisheries 2011). This research aims to give an insight into public attitudes in New Zealand around pain and welfare in fish and catchand-release angling. It may also help to identify whether fish welfare issues are of concern to the wider public. There are few regulations New Zealand's anglers must adhere to when undertaking CRA. Identification of concerns held by the public of New Zealand regarding CRA may function to encourage dialogue on whether or not future improvements in legislation or process are required. Especially those that cover the welfare of recreationally caught fish. It may also serve to highlight a need for education or provision of guidelines for more 'fishfriendly' angling practice among New Zealand's recreational anglers.

\section{Materials and methods}

\section{The survey}

The survey was developed through a review of the literature on fish, CRA welfare issues and attitudes towards animal welfare. It was distributed nationally, by assistants in each region of New Zealand (as determined by the New Zealand census), at a neutral venue (eg supermarket) to individuals over 18 years of age. The assistants were not associated with the research or its outcomes. A total of 700 surveys were distributed and freepost envelopes were provided to facilitate return. Questionnaires were distributed to regions of the country in proportion to the population within the region (as gathered from census data) so more populated areas were allotted more surveys. This research was conducted under approval granted by the Unitec Research Ethics Committee.

The survey cover page included a definition of CRA (Cooke \& Sneddon 2007). It also explained how to use the linear rating scale (see below) and provided a date of return. Contact information was provided for questions or comments about the survey and an indication that participation was entirely voluntary. Demographic information collected included sex, age and region. Subsequent questions assessed participation in and acceptability of CRA and attitudes and opinions on angling practices that may affect welfare (eg use of correct tackles) and the pain perception of fish. As this survey sought to assess public opinions with respect to pain and as all respondents have an experiential reference point, an absolute definition of pain was not provided. Reminders were unable to be sent.

Some questions required participants to respond by placing a single vertical line through a horizontal line $0-100 \mathrm{~mm}$ long (ie the perceived degree to which fish could experience pain and the degree to which CRA caused pain (0 not at 
Table I Factor loadings after rotation using extraction method Principal Component Analysis (PCA) with rotation method Oblimin with Kaiser Normalisation for the nine components within a questionnaire conducted throughout New Zealand investigating attitudes towards catch-and-release angling (CRA) and perceptions of pain and welfare in fish.

\begin{tabular}{lll}
\hline Parameter & Component I (angling practices) & Component 2 (pain and survival) \\
\hline Importance of air exposure & 0.855 & \\
Importance of hook location & 0.853 & \\
Importance of handling & $0.84 I$ & \\
Importance of types of tackles & 0.680 & \\
Importance of angling duration & 0.632 & 0.90 I \\
Importance of angling during key life stages & 0.616 & 0.873 \\
Extent to which CRA causes pain to fish & & 0.599 \\
Extent to which fish feel pain & & \\
Fish survival following CRA & & \\
\hline
\end{tabular}

all-100 extreme pain); the perceived likelihood of survival following CRA (0 not at all-100 certain). Five-point Likert scales were used for questions that considered angling practices that potentially impact upon the welfare of fish (ie angling duration, air exposure, handling time, tackle used, angling during key life stages, location of hook) where: $1=$ not important; 2 = somewhat important; 3 = important; $4=$ very important; and $5=$ extremely important.

\section{Data handling}

All information was entered into Statistical Package for the Social Sciences (SPSS) version 18.0 for Windows (SPSS Inc, Chicago, IL, USA) for analysis. To reduce the number of potential variables for analysis we conducted a Principal Component Analysis (PCA) on nine survey items using Oblimin with Kaiser normalisation as the rotation method. The factor loadings after rotation are given in Table 1. Components one and two in combination explained $60.8 \%$ of the variance within the results. Based on the nature of the survey questions contributing to the two components, component one was taken to be indicative of attitudes towards angling practices and component two was related to the capacity of fish to feel pain and the impacts of CRA on fish in terms of pain and survival. A reliability analysis was conducted on responses related to components one and two and both had high reliabilities, Cronbach's $\alpha=0.845$ (angling practices) and Cronbach's $\alpha=0.736$ (pain and survival) (see Table 1).

$T$-Tests were used to determine if there were significant differences in the component scores generated through PCA, associated with gender of the respondent and whether or not they participated in CRA. KruskalWallis tests were then performed to determine differences in component scores associated with respondents' ages, acceptability of CRA and whether anglers should follow CRA guidelines.
Table 2(a) Descriptive data for respondents completing a survey conducted throughout New Zealand to investigate attitudes towards catch-and-release angling (CRA) and perceptions of pain and welfare in fish.

\begin{tabular}{|c|c|c|}
\hline Parameter & $\mathbf{n}$ & $\%$ \\
\hline \multicolumn{3}{|l|}{ Gender } \\
\hline Female & 215 & 49.2 \\
\hline Male & 221 & 50.6 \\
\hline \multicolumn{3}{|l|}{ Age (years) } \\
\hline $18-25$ & 96 & 22.0 \\
\hline $26-35$ & 75 & 17.2 \\
\hline $36-45$ & 61 & 14.0 \\
\hline $46-55$ & 91 & 20.8 \\
\hline $56-65$ & 71 & 16.2 \\
\hline $66+$ & 43 & 9.8 \\
\hline \multicolumn{3}{|c|}{ Participation in CRA } \\
\hline Yes & 66 & I5. I \\
\hline No & 370 & 84.7 \\
\hline \multicolumn{3}{|c|}{ Is CRA acceptable? } \\
\hline Yes & 284 & 65.0 \\
\hline No & 93 & 21.3 \\
\hline Don't know & 58 & 13.3 \\
\hline \multicolumn{3}{|c|}{ Should CRA have Guidelines/Regulations? } \\
\hline Yes & 334 & 76.4 \\
\hline No & 45 & 10.3 \\
\hline Unsure & 55 & 12.6 \\
\hline
\end{tabular}

Range total, $n=434-437$ discrepancies caused by missing or invalid responses. 
Table 2(b) Median score and interquartile range for linear rating scale questions based on all responses to a survey conducted throughout New Zealand investigating attitudes towards catch-and-release angling (CRA) and perceptions of pain and welfare in fish.

\begin{tabular}{llll}
\hline Parameter & Valid (n) & Median & Inter-quartile range (25-75\%) \\
\hline Fish survival following CRA score (0-100) & 426 & 59 & $46-76$ \\
Fish pain perception score (0-100) & 427 & 57 & $34-77$ \\
CRA pain infliction score (0-100) & 427 & 51 & $37-72$ \\
\hline
\end{tabular}

Range total, $n=426-427$.

Table 3 Mean ( \pm SD) and significance of each component in relation to individual parameters based on responses to a survey conducted throughout New Zealand investigating attitudes towards catch-and-release angling (CRA) and perceptions of pain and welfare in fish.

\begin{tabular}{|c|c|c|}
\hline Parameter & CI mean ( \pm SD) & C2 mean ( \pm SD) \\
\hline \multicolumn{3}{|l|}{ Gender } \\
\hline Female & $-0.15( \pm 0.93)$ & $-0.29( \pm 0.98)$ \\
\hline \multirow[t]{2}{*}{ Male } & $0.15( \pm 1.05)$ & $0.30( \pm 0.93)$ \\
\hline & $\begin{array}{l}t=3.147, \mathrm{df}=415 \\
P=0.0002\end{array}$ & $\begin{array}{l}t=6.363, \mathrm{df}=415, \\
P<0.001\end{array}$ \\
\hline \multicolumn{3}{|l|}{ Age (years) } \\
\hline $18-25$ & $0.03( \pm 0.83)$ & $0.34( \pm 0.96)$ \\
\hline $26-35$ & $-0.02( \pm 0.97)$ & $0( \pm 0.93)$ \\
\hline $36-45$ & $-0.38( \pm 1.30)$ & $-0.04( \pm 0.94)$ \\
\hline $46-55$ & $0.22( \pm 0.85)$ & $-0.06( \pm 1.01)$ \\
\hline $56-65$ & $-0.09( \pm 1.07)$ & $-0.31( \pm 1.06)$ \\
\hline \multirow[t]{2}{*}{$66+$} & $0.15( \pm 1.03)$ & $-0.07( \pm 1.01)$ \\
\hline & $\begin{array}{l}\chi^{2}=9.885, \mathrm{df}=5 \\
P=0.079\end{array}$ & $\begin{array}{l}\chi^{2}=19.930, \mathrm{df}=5, \\
P<0.001\end{array}$ \\
\hline \multicolumn{3}{|c|}{ Participation in CRA } \\
\hline Yes & $-0.18( \pm 0.99)$ & $-0.52( \pm 0.88)$ \\
\hline \multirow[t]{2}{*}{ No } & $0.03( \pm 1.00)$ & $0.10( \pm 0.99)$ \\
\hline & $\begin{array}{l}t=-1.515, \mathrm{df}=415 \\
P=0.131\end{array}$ & $\begin{array}{l}t=-4.675, \mathrm{df}=415, \\
P<0.001\end{array}$ \\
\hline \multicolumn{3}{|c|}{ Is CRA acceptable? } \\
\hline Yes & $-0.11( \pm 0.87)$ & $-0.36( \pm 0.86)$ \\
\hline No & $0.37( \pm 1.04)$ & $0.82( \pm 0.86)$ \\
\hline \multirow[t]{2}{*}{ Don't know } & $-0.10( \pm 1.36)$ & $0.38( \pm 0.91)$ \\
\hline & $\begin{array}{l}\chi^{2}=38.178, \mathrm{df}=2, \\
P<0.001\end{array}$ & $\begin{array}{l}\chi^{2}=104.749, \mathrm{df}=2, \\
P<0.001\end{array}$ \\
\hline \multicolumn{3}{|c|}{$\begin{array}{l}\text { Guidelines/Regulations } \\
\text { during CRA }\end{array}$} \\
\hline Yes & $0.15( \pm 0.96)$ & $0.16( \pm 0.95)$ \\
\hline No & $-0.63( \pm 1.00)$ & $-0.78( \pm 0.90)$ \\
\hline \multirow[t]{2}{*}{ Unsure } & $-0.40( \pm 0.93)$ & $-0.32( \pm 0.99)$ \\
\hline & $\begin{array}{l}\chi^{2}=38.178, \mathrm{df}=2, \\
P<0.001\end{array}$ & $\begin{array}{l}\chi^{2}=39.753, \mathrm{df}=2, \\
P<0.001\end{array}$ \\
\hline
\end{tabular}

$\mathrm{Cl}$ : Component I (angling practices); C2: Component 2 (pain and survival). A higher mean value indicates a more positive attitude or greater concern.

\section{Results}

A total of 437 surveys were returned (response rate of $62.4 \%$ ) from all 20 designated regions with the exception of the West Coast of the South Island. The response rate from each region was approximately proportional to the relative percentage of population that live in each area of New Zealand based on the 2006 census (Statistics New Zealand 2006).

\section{Descriptive data}

The proportion of male and female respondents was similar (49.5\% female; $50.6 \%$ male) and the number of participants in CRA was low (15\%) but comparable to the $20 \%$ reported by the Ministry of Fisheries (2011) for the total population of New Zealand. The majority of respondents considered CRA an acceptable pastime (65\%) and also considered it an activity that should be associated with specific welfare regulations or guidelines (Table 2[a]). The majority of respondents indicated they believed fish were able to feel pain to some degree, and that CRA compromised survival (Table 2[b]).

Factors influencing attitudes towards impacts of CRA

Only $1.2 \%$ of respondents believed that fish had no capacity to feel pain, and only a small number believed CRA reduced survival to zero $(0.9 \%)$. Female respondents showed greater concern than male respondents for both appropriate CRA practices, and pain and survival in fish. Similarly, respondents who felt anglers should follow regulations and guidelines during CRA showed greater concern for both angling practice, and pain and survival. Respondents who found CRA an unacceptable pastime were also more concerned with angling practice, and pain and survival than those that considered it to be acceptable (see Table 3). Older respondents and those that participated in angling showed no significant differences compared to younger respondents and non-anglers when it came to concern for angling practices. However, a significant difference was evident in their concern for pain and survival in fish with the former showing less concern than the latter.

\section{Discussion}

Although perceptions varied widely, our results indicate that most respondents believed that fish were capable of experiencing moderate to extreme pain (inter-quartile range 34-77), and that fish experienced this during CRA (see Table 2[b]). This contrasts with a similar study from North America (Hasler et al 2011) which found only 35-58\% of respondents believed fish could feel pain. However, as both Hasler et al (2011) and the current study obtained responses 
from comparatively small samples of source populations, it is difficult to extrapolate the results to the larger population with much certainty. It would be worthwhile to conduct further research with both a larger sample, and more comprehensive scope in order to understand the true position of New Zealanders on issues of fish welfare.

Females appeared more concerned about fish welfare and scored the capacity of fish to feel pain higher and the likelihood of fish survival lower following CRA than males. This finding is consistent with research that indicates gender differences exist in pain perception. Under experimental conditions females displayed greater pain sensitivity compared with males for most pain modalities (Fillingim et al 2009) which, in turn, may increase empathy for others (Han et al 2008). Similarly, women have been found to score far higher on empathy-based questioning as compared to men (Rueckert \& Naybar 2008). Studies involving pet attitude scales, animal empathy scales, and pain assessment instruments have shown that females score significantly higher than males (Ellingsen et al 2010) and that males are more supportive of animal use and are more likely to engage in activities such as recreational hunting than females (Knight et al 2004; Herzog 2007).

Age of respondents did not significantly affect attitudes towards angling practices. However, the concern for pain and survival of fish decreased with increased respondent age. Respondents aged between 18 and 25 scored their response significantly higher than the $66+$ age group. As Kendall et al (2006) found, younger people tend to be more concerned about animal well-being than the older population. Nibert (1994) and Kellert (1996) both report that adults in their early thirties or younger are most concerned with animal wellbeing. Animal welfare science has become a significant research area relatively recently (Braithwaite 2010) and the increased 'awareness' in recent times may explain why younger respondents are more aware of animal pain and welfare-related issues. There was no difference in importance placed upon angling practices between age groups. This suggests that older age groups may focus on processes which directly improve effective fishing and incidentally promote better welfare. More theoretical or supposed measures of welfare (ie pain and survival) could be less important.

There were no significant differences between participants in CRA $(\mathrm{n}=66 ; 15.1 \%)$ as opposed to non-participants for component 1 scores showing that non-anglers are as concerned with angling practices as those who fish. Use of correct techniques and equipment are important if compromised fish welfare is to be minimised (Meka \& McCormick 2005), however improvements in fish welfare may be incidental. Other research has indicated that most anglers believe that they know the correct release techniques and have the correct equipment for releasing fish (Arlinghaus et al 2007), however this was not addressed in the current study. Braithwaite (2010) suggested that, with potential suffering in mind, many anglers actively choose to use fishing gear and methods which minimise suffering. Our findings suggest that, although anglers and non-anglers show similar levels of concern for the impact of angling practices (component 1), anglers' concerns for pain and suffering in fish (component 2) is significantly lower than that of non-anglers (Table 3). Reduced empathy has previously been observed in those who routinely utilise or kill animals (Knight \& Barnett 2006; Taylor \& Signal 2006) and it is likely this effect that explains the observed difference. Therefore, the best route for improving fish welfare will be through provision of education to anglers on positive angling practices (Meka \& McCormick 2005; Tsuboi et al 2006; Cooke \& Sneddon 2007). Education surrounding the subjective experiences of fish may be less effective in the angling community as opposed to the wider community.

Sixty-five percent of respondents believe CRA is an acceptable pastime. Acceptability of CRA significantly influenced both attitudes to angling practices and pain and survival in fish. Those who found CRA unacceptable as a pastime provided significantly higher scores for both components as compared to those who found it acceptable or were unsure (Table 3). It is logical that people who find angling unacceptable possess more stringent attitudes and opinions on angling practices and fish pain and survival. Despite clear concern within the sample population for pain and survival of fish, for the majority, the acceptability of angling is likely linked to cultural and/or social norms which outweigh the collateral costs in terms of fish welfare. Arlinghaus et al (2007) state "the implication is that catch-and-release is, in principle, only acceptable under animal welfare philosophies". As the majority of respondents in this study (76.4\%) felt anglers should have to follow welfare guidelines and regulations when angling, it is plausible that the New Zealand public may support this assertion.

Those that felt welfare guidelines and regulations were not necessary had significantly lower scores for both the importance of angling practices and pain and survival of fish when compared to those who were either unsure or felt that regulation was required (Table 3). This suggests those who are less concerned with good angling practices or pain and survival of fish during CRA are also those that consider it unnecessary to have regulations to improve or safeguard fish welfare.

\section{Animal welfare implications}

This study is one of very few which address public concern for the welfare of fish and will hopefully provide a platform for further discussion. While the small sample size of the current study suggests a degree of caution when drawing conclusions, the research does suggest further research would be highly valuable.

In New Zealand there are currently relatively few guidelines and regulations governing the welfare of wild caught fish and CRA. The New Zealand Ministry of Fisheries (2007) released Guidelines for Releasing Under-sized Fish which explained correct handling of fish once caught to increase their chance of survival upon release. However, beyond this, other guidelines and regulations only refer to catch and size limits and restrictions on tackles and lures. Although it was pointed out by some respondents to the survey that regulations would be hard to police, this survey suggests that a proportion of New Zealanders are likely to support future 
welfare regulations to ensure the welfare of fish is not unnecessarily compromised. Consideration of fish welfare regulations must allow for the fact that the majority consider CRA to be an acceptable pastime. Our results indicate there may be a desire for more public education around CRA, and it is likely many people would be responsive to further discussion of fish welfare in the New Zealand context.

\section{Acknowledgements}

This study was sponsored by the Royal New Zealand Society for the Prevention of Cruelty to Animals (RNZSPCA). Thanks go to all the people who assisted in distribution of the surveys and those who answered the questionnaires.

\section{References}

Aas O, Thailing CE and Ditton RB 2002 The discourse about catch-and-release fishing in Europe: implications for North America. American Fisheries Society Symposium 30: 20I-204

Arlinghaus R, Cooke SJ, Lyman J, Policansky D, Schwab A, Suski C, Sutton SG and Thorstad EB 2007 Understanding the complexity of catch-and-release in recreational fishing: an integrative synthesis of global knowledge from historical, ethical, social, and biological perspectives. Reviews in Fisheries Science 15: 75-167. http://dx.doi.org/10.1080/1064 |260601 | 49432

Arlinghaus R, Klefoth T, Cooke SJ, Gingerich A and Suski C 2009a Physiological and behavioural consequences of catchand-release angling on northern pike (Esox lucius L). Fisheries Research 97: 223-233. http://dx.doi.org/10.1016/j.fishres. 2009.02.005

Arlinghaus R, Schwab A, Cooke SJ and Cowx IG 2009b Contrasting pragmatic and suffering-centres approaches to fish welfare in recreational angling. Journal of Fish Biology 75(I0): 24482463. http://dx.doi.org// 0. I I I I/j. 1095-8649.2009.02466.x

Arlinghaus R, Schwab A, Riepe C and Teel T 2012 A primer on anti-angling philosophy and its relevance for recreational fisheries in urbanized societies. Fisheries 37(4): I53-164. http://dx.doi.org/I0.1080/036324I5.2012.666472

Bartholomew A and Bohnsack JA 2005 A review of catchand-release angling mortality with implications for no-take reserves. Reviews in Fish Biology and Fisheries 15: 129-154. http://dx.doi.org//0.1007/s I I 160-005-2175-I

Braithwaite VA 2010 Do Fish Feel Pain? Oxford University Press: New York, USA

Braithwaite VA and Boulcott P 2007 Pain perception, aversion and fear in fish. Diseases of Aquatic Organisms 75: 131-138. http://dx.doi.org//0.3354/dao075 I 3 |

Chandroo KP, Duncan IJH and Moccia RD 2004 Can fish suffer? Perspectives on sentience, pain, fear and stress. Applied Animal Behaviour Science 86: 225-250. http://dx.doi.org/ 10.1016/j.applanim.2004.02.004

Cooke SJ and Cowx IG 2004 The role of recreational fishing in global fish crises. Bioscience 54(9): 857-859. http://dx.doi.org// 0.164 I/0006-3568(2004)054[0857:TROR$\mathrm{FI}] 2.0 . \mathrm{CO} ; 2$
Cooke SJ, Donaldson MR, O'Connor CM, Raby GD, Arlinghaus R, Danylchuk AJ, Hanson KC, Hinch SC, Clark TD, Patterson DA and Suski CD 2013 The physiological consequences of catch-and-release angling: perspectives on experimental design, interpretation, extrapolation and relevance to stakeholders. Fisheries Management and Ecology 20: 268-287

Cooke SJ and Sneddon LU 2007 Animal welfare perspectives on recreational angling. Applied Animal Behaviour Science 104: 176198. http://dx.doi.org//0.1016/j.applanim.2006.09.002

Cooke SJ and Suski CD 2005 Do we need species-specific guidelines for catch-and-release recreational angling to effectively conserve diverse fishery resources? Biodiversity and Conservation 1 4: I 195-2005. http://dx.doi.org// 0. 1007/s I053 I-004-7845-0

Davie PS and Kopf RK 2006 Physiology, behaviour and welfare of fish during recreational fishing and after release. New Zealand Veterinary Journal 54(4): I6I-I72. http://dx.doi.org/I0.1080/0048 0169.2006 .36690

Dorow M and Arlinghaus R 2012 The relationship between personal commitment to angling and the opinions of German anglers towards the conservation and management of the European eel (Anguilla anguilla). North American Journal of Fisheries Management 32(3): 466-479. http://dx.doi.org//0.1080/0275594 7.2012 .680006

Dunlop R, Millsopp S and Laming P 2006 Avoidance learning in goldfish (Carassius auratus) and trout (Oncorhynchus mykiss) and implications for pain perception. Applied Animal Behaviour Science 97: 255-27I. http://dx.doi.org//0.1016/j.applanim.2005.06.018

Ellingsen K, Zanella AJ, Bjerkas E and Indrebo A 2010 The relationship between empathy, perception of pain and attitudes toward pets among Norwegian dog owners. Anthrozoös 23: 231243. http://dx.doi.org//0.2752//753037 I0X 1275045 I 25893 |

Environment Agency 2010 Public attitudes to angling 2010. Environment Agency: Rio House, Bristol, UK

Food and Agriculture Organization of the United Nations (FAO) 2012 The State of World Fisheries and Aquaculture. FAO Fisheries and Aquaculture Department: Rome, Italy

Fillingim RB, King CD, Ribeiro-Dasilva MC, RahimWilliams B and Riley JL 2009 Sex, gender, and pain: a review of recent clinical and experimental findings. The Journal of Pain 10 : 447-485. http://dx.doi.org/10.1016/j.jpain.2008.12.001

Han S, Fan Y and Mao L 2008 Gender difference in empathy for pain: an electrophysiological investigation. Brain Research 1 196: 85-93. http://dx.doi.org//0.1016/j.brainres.2007.12.062

Hasler CT, Colotelo AH, Rapp T, Jamieson E, Bellehumeur K, Arlinghaus R and Cooke SJ 201 I Opinions of fisheries researchers, managers, and anglers towards recreational fishing issues: an exploratory analysis for North America. American Fisheries Symposium 75: 51-74

Herzog HA 2007 Gender differences in human-animal interactions: a review. Anthrozoös 20: 7-2I. http://dx.doi.org/10.2752/0 89279307780216687

Huntingford FA, Adams C, Braithwaite VA, Kadri S, Pottinger TG, Sandøe P and Turnbull JF 2006 Current issues in fish welfare. Journal of Fish Biology 68(2): 332-372. http://dx.doi.org//0. I I I /j.0022-I I I 2.2006.00 I046.x 
Kellert SR 1996 The Value of Life: Biological Diversity and Human Society. Island Press: Washington, DC, USA

Kendall HA, Lobao LM and Sharp JS 2006 Public concern with animal well-being: place, social structural location, and individual experience. Rural Sociology 7I: 399-428. http://dx.doi.org/ 10.1526/00360II06778070617

Knight D and Barnett L 2006 Justifying attitudes toward animal use: a qualitative study of people's views and beliefs. Anthrozoös 2I: 31-42. http://dx.doi.org//0.2752/08927 $9308 \times 274047$

Knight S, Vrij A, Cherryman J and Nunkoosing K 2004 Attitudes towards animal use and belief in animal mind. Anthrozoös I 7: 43-62. http://dx.doi.org//0.2752/08927930478699/945

Meka JM and McCormick SD 2005 Physiological response of wild rainbow trout to angling: impact of angling duration, fish size, body condition, and temperature. Fisheries Research 72: 31 I-322. http://dx.doi.org/I0.1016/j.fishres.2004.10.006

Ministry of Fisheries 2007 November 16 Guidelines for Releasing Undersized Fish. http://www.fish.govt.nz

Minstry of Fisheries 2011 Annual Report 2010/2011. http://www.fish.govt.nz

Nibert DA 1994 Animal rights and human social issues. Society and Animals 2: II5-124. http://dx.doi.org//0.1/63//56853 094X00135

Rose JD 2002 The neurobehavioral nature of fishes and the question of awareness and pain. Reviews in Fisheries Science 10: 1-38. http://dx.doi.org//0.1080/20026491051668
Rose JD 2007 Anthropomorphism and 'mental welfare' of fishes. Diseases of Aquatic Organisms 75: 139-154. http://dx.doi.org/ 10.3354/dao075139

Rueckert L and Naybar N 2008 Gender differences in empathy: the role of the right hemisphere. Brain and Cognition 67: 162167. http://dx.doi.org/10.1016/j.bandc.2008.01.002

Sneddon LU 2003 The evidence for pain in fish: the use of morphine as an analgesic. Applied Animal Behaviour Science 83: I53-162. http://dx.doi.org//0.1016/S0168-I59I(03)00II3-8

Sneddon LU, Braithwaite VA and Gentle MJ 2003 Do fishes have nociceptors? Evidence for the evolution of vertebrate sensory system. Proceedings of the Royal Society 270: III5-II2I. http://dx.doi.org// 0.1098/rspb.2003.2349

Statistics New Zealand 20062006 Census. http://www.stats.govt.nz

Taylor $\mathbf{N}$ and Signal TD 2006 Community demographics and the propensity to report animal cruelty. Journal of Applied Animal Welfare Science 9: 20l-210. http://dx.doi.org/I0.1207/s I5327604jaws0903_2

Tsuboi J, Morita K and Ikeda H 2006 Fate of deep-hooked white-spotted charr after cutting the line in a catch-and-release fishery. Fisheries Research 79: 226-230. http://dx.doi.org/10.1016 /j.fishres.2006.03.002

Wallmo K and Gentner B 201 I Catch-and-release fishing: a comparison of intended and actual behaviour of marine anglers. North American Journal of Fisheries Management 28(5): I459-I47I. http://dx.doi.org/ 10.1577/M07-062.I 